\title{
An Optimal Dynamic Generation Scheduling for a Wind-Thermal Power System*
}

\author{
Xingyu Li, Dongmei Zhao \\ School of Electrical and Electronic Engineering, North China Electric Power University, Beijing, China \\ Email: lxylyxy123@ncepu.edu.cn
}

Received March, 2013

\begin{abstract}
In this paper, a dynamic generation scheduling model is formulated, aiming at minimizing the costs of power generation and taking into account the constraints of thermal power units and spinning reserve in wind power integrated systems. A dynamic solving method blended with particle swarm optimization algorithm is proposed. In this method, the solution space of the states of unit commitment is created and will be updated when the status of unit commitment changes in a period to meet the spinning reserve demand. The thermal unit operation constrains are inspected in adjacent time intervals to ensure all the states in the solution space effective. The particle swarm algorithm is applied in the procedure to optimize the load distribution of each unit commitment state. A case study in a simulation system is finally given to verify the feasibility and effectiveness of this dynamic optimization algorithm.
\end{abstract}

Keywords: Generation Scheduling; Dynamic Optimization; Wind Power; Particle Swarm Optimization

\section{Introduction}

The proportion of wind energy in the pattern of world energy has been increasing since the beginning of the twenty-first century. Since wind power plays a positive role in energy saving and reducing emissions of pollutants, power companies should transport and distribute wind power electricity as much as possible. However, when large-scale wind power accesses the power system, the generation scheduling and reserve need to be re-arranged and adjusted due to intermittent and variable characteristic of wind power output.

Currently, researchers at home and abroad have done a lot of work. In the study of optimal scheduling model, in literature [1], a dynamic economic scheduling model is built considering the random variation of the wind speed; and in dynamic optimization model, the unit ramp rate must be a constraint [2]. In the research of unit commitment for power systems with wind farms, the credible data of wind speed and wind power output are needed, in [3], the wind speed is predicted by time series method based on neural network.

The optimization of unit scheduling is a large-scale nonlinear mixed integer model, and a variety of algorithms are used to solve the problem. Traditional methods like priority list [4-5], LaGrange Relaxation and dynamic programming have been applied to solve the

*The National High Technology Research and Development of China 863 Program (2012AA050201). model. With the development of artificial intelligence algorithms, a variety of intelligent algorithms, such as genetic algorithms [6], ant colony algorithm [7], particle swarm optimization [8-9] have also been used to deal with optimization scheduling.

In this paper, an optimal generation scheduling model is established, aiming at the minimum cost of conventional fuel energy in a wind-thermal power system, and a dynamic solution method combined with particle swarm optimization algorithm is proposed. In the solution process, spinning reserve is firstly calculated to ensure a unit commitment state valid considering wind power integrated. The load distribution of thermal power units is done using the Particle Swarm Optimization (PSO) algorithm. After analyzing every unit commitment state in each time period, the ramp rate, operation and outage time constraints are inspected to make a refined arrangement of generation scheduling. Finally, a case in a test system is given with an optimal scheduling plan to show the feasibility and effectiveness of this solution method.

\section{Objective Function and Formulation}

In a power system, the operation status and output power of the generators should be regulated as the system load changes. In the study of the power system operation scheduling, a scheduling period is usually divided into several time intervals, and in each interval, the load is constant. The optimization generation scheduling prob- 
lem is determining a unit commitment and load dispatching plan to minimize the costs of power generation and ensure operation safety, power balance, reserve demand and other constraints of generators in a scheduling period. It can be formulated as follows.

\subsection{Objective Function}

In the wind-thermal power system, wind turbines do not consume fossil fuels. The objective of the optimal scheduling model is to minimize the start consumption and power generation fuel costs of conventional thermal power units in the system scheduling period. Thus the function is defined as

$$
\min \left\{\sum_{t=1}^{T} \sum_{i=1}^{N}\left[u_{i, t} f\left(P_{i, t}\right)+u_{i, t}\left(1-u_{i, t-1}\right) S_{i, t}\right]\right\}
$$

where $T$ is scheduling period, divided into24 intervals, $N$ is number of thermal power units, $\mathrm{u}$ i, $\mathrm{t}$ is status (on/off) of unit i in period $t, P i$, $t$ is the active output, $S i$ is startup cost of unit $i$.

$f(P i, t)$ is the cost of thermal power unit and can be approximately described by quadratic function:

$$
f\left(P_{i, t}\right)=a_{i}+b_{i} P_{i, t}+c_{i} P_{i, t}^{2}
$$

where, $a_{i}, b_{i}, c_{i}$ are the coefficients of consumption characteristics. Startup cost $S_{i}$ is a exponential function of the unit outage time, the longer outage time, the greater the startup cost [10]. As the scheduling period is 24 hours, $S_{i}$ is regarded as a constant for each unit. And the objective function is subjected to following constraints.

\subsection{Constraints}

1) System constraints

a) Power balance

$$
\sum_{i=1}^{N} P_{i, t}+P_{W t}-P_{D t}=0
$$

$P_{W t}$ is the output of wind farm within the period $t ; P_{D t}$ is the load thermal power units must supply in the time period $t$.

b) Spinning reserve requirements

Positive spinning reserve capacity:

$$
\begin{aligned}
& R_{u, i}^{t}=\min \left(P_{i, \max }-P_{i, t}, U_{R i} T_{1}\right) \\
& \sum_{i=1}^{N} u_{i, t} R_{u, i}^{t} \geq R_{D}^{t}+w_{u} \% P_{w t}
\end{aligned}
$$

Negative spinning reserve capacity:

$$
\begin{aligned}
& R_{d, i}^{t}=\min \left(P_{i, t}-P_{i, \min }, D_{R i} T_{1}\right) \\
& \sum_{i=1}^{N} u_{i, t} R_{d, i}^{t} \geq w_{d} \%\left(P_{w, \text { max }}-P_{w t}\right)
\end{aligned}
$$

where $R^{t} D$ is load reserve, $w_{u} \%$ and $w_{d} \%$ are influence coefficients caused by wind power prediction error; $P_{w, \max }$ is the maximum output of the wind farm; $T_{1}$ represents one hour; $D_{R i}$ and $U_{R i}$ are respectively for the unit down ramp rate and upward ramp rate.

2) Thermal unit constraints

a) Minimum operation and outage time constraints

$$
\begin{aligned}
& \left(T_{i, t-1}^{o n}-T_{i, \text { min }}^{o n}\right)\left(u_{i, t-1}-u_{i, t}\right) \geq 0 \\
& \left(T_{i, t-1}^{\text {off }}-T_{i, \text { min }}^{\text {off }}\right)\left(u_{i, t}-u_{i, t-1}\right) \geq 0
\end{aligned}
$$

where $T_{i, t}^{o n}$ and $T_{i, t}^{o f f}$ stands respectively for accumulated continuous operation and outage time of unit $i$ till period $t$.

b) Ramp rate constraint

$$
-D_{R i} \leq P_{i, t}-P_{i, t-1} \leq U_{R i}
$$

C) Maximum and minimum power limits

$$
P_{i, \min } \leq P_{i, t} \leq P_{i, \max }
$$

\subsection{Wind Power Output Analysis}

The wind power output is random mainly caused by the random variation of the primary energy wind itself. The wind turbines in the same wind farm have almost the same wind direction and wind speed. Therefore, it is possible to simulate power output of a wind farm by an equivalent wind turbine [3].

A function of wind power output and wind speed can be described by an approximate piecewise function expression; and the equation between the cut-in speed and cut-out wind fits a cubic function [3].

$$
P_{w}=\left\{\begin{array}{lc}
0, & v<v_{C I} \text { or } v \geq v_{C O} \\
\frac{v^{3}}{v_{R}^{3}-v_{C I}^{3}} P_{R}-\frac{v_{C I}^{3}}{v_{R}^{3}-v_{C I}^{3}} P_{R}, & v_{C I} \leq v \leq v_{R} \\
P_{R}, & v_{R} \leq v<v_{C O}
\end{array}\right.
$$

where $P_{R}$ is the rated power of the wind turbine. The wind power output used in the optimal scheduling is determined by the following method. First some sample values of wind speed are chosen from the historical statistics data of wind speed randomly in time order of a day. And then, the wind speed values are predicted in the method based on time series method and artificial neural network [11]. The power output of a wind farm is the sum of the output of each turbine using Equation (12) in every interval. The total power output wind farms generate can be approximately taken as the sum of each wind farm output.

\section{Method for Solving the Model}

\subsection{Create the Set of Unit Commitment}

The mathematical model in this paper is a certain kind of 
dynamic programming problem, because in each period of the scheduling period, the load distribution must be determined for the current unit commitment status and suitable results of unit commitment must be recorded. In a practical power system, the load curve within one day will increase to peak and then decline in the trend, so in some different periods of one day, the load command and the state of unit commitment can be fully consistent with that of other period; and the output of generating units could be different due to the Increase and decrease of the load. Therefore, in the process of solving the generating model, a set of states of unit commitment can be set up and updated from the first interval.

In fact, the establishment of the set of states of each unit is simple and feasible. The thermal unit can be sorted in ascending order by comparing their average fuel cost per hour. A state of unit commitment is then generated to ensure that all the installed capacity is larger than the sum of load and reserve for the system operation. The element in the set can be described using a vector. The vectors of all the intervals reflect a certain unit commitment plan and it shows as follows.

$$
\left[u_{1}^{1} u_{2}^{1} \cdots u_{N}^{1}, u_{1}^{2} u_{2}^{2} \cdots u_{N}^{2}, \cdots, u_{1}^{T} u_{2}^{T} \cdots u_{N}^{T}\right]
$$

$u_{i}^{t}$ is either 0 or 1 , and 0 or 1 indicates that a unit is OFF or ON.

\subsection{Determine the Maximum Wind Power and Reserve}

The accuracy of wind power forecast is not exact and precise, so in the generation scheduling the maximum of wind power systems can accept should be determined in order to adjust spinning reserve. In an interval, when the current status of unit commitment does not meet the reserve demand, a new unit may start up or an old one shuts down to satisfy the constraints (3), (5) and (7). In [12], considering that the total ramp capacity of conventional thermal units is near the expected wind power fluctuations, the largest wind power penetration level can be expressed as.

$$
\begin{gathered}
P_{W t}=\min \left[P_{t}^{W T 1}, P_{t}^{W T 2}\right] \\
P_{t}^{W T 1}=\sum_{j=1}^{N W} P_{w, j} \\
P_{t}^{W T 2}=\left(P_{D t}-\sum_{i=1}^{N} u_{i}^{t} P_{i, \min }\right) /(1+r \%)
\end{gathered}
$$

where NW is the number of wind farms, $r \%$ is coefficient of additional reserve proportion, and $P_{w, j}$ is described in section 2 .

\subsection{Application of Particle Swarm Optimization}

The basic PSO algorithm is used here to complete the load dispatching for every unit commitment state in each interval. Define the unit output value at time period $t$ as the position of the particle, then the particle $m$ at time period $t$ can be expressed,

$$
X_{m}^{t}=\left[P_{1}^{t} P_{2}^{t} \cdots P_{N}^{t}\right]
$$

The algorithm begins where the unit output is near the rated capacity or active power at the minimum ratio of consumption, and in the researching the speed does not exceed $50 \mathrm{MW}$ and the fitness function is the operation costs in an interval, referring equation (1).

Particle swarm optimization speed and position update formula shows below:

$$
\begin{gathered}
V_{m}^{k+1, t}=\omega V_{m}^{k, t}+c_{1} r_{1}\left(p_{m}^{t}-X_{m}^{k, t}\right) \\
+c_{2} r_{2}\left(g_{m}^{t}-X_{m}^{k, t}\right) \\
X_{m}^{k+1, t}=X_{m}^{k, t}+V_{m}^{k+1, t}
\end{gathered}
$$

where $V^{k, t} m$ is the speed in period $t$ of the m-th particle, $X^{k, t} m$ stands for the position of the particle, $p^{t} m$ for the optimal position after $\mathrm{k}$ iterations, $g^{t} m$ for the optimal position among all particles after $\mathrm{k}$ iterations.

\subsection{Overall Solution Process}

Step 1: Read the system data and set values of algorithm parameters.

Step 2: The time interval $t=1$, create the initial set of states of unit commitment; $t>1$, begin next-stage search.

Step 3: Determine the maximum wind power and reserve of current state, and inspect whether it is necessary to open a new unit or shut down one for meeting reserve constraints, minimum operation and outage time constraints. If necessary, update the state and the set.

Step 4: Complete the load distribution of this state in the interval using PSO.

Step 5: Inspect the boundary constraints (10) and (11). If neither is met, give up the state and delete it from the set. If only one is obeyed, adjust the power output to the boundary value.

Step 6: Still another state to be calculated? Yes, turn back to step 3; otherwise, go next.

Step 7: Record all the states till current interval $t$ and sum up cumulative objective function values.

Step 8: Is this last interval of the period? If not, set $t=t+1$, go back to step 2. If true, compare the objective value of each scheduling plan consisting of all state from first interval to last. Output the best one whose cost is lower than any other. 
Step 9: After output generation scheduling plan, the process is terminated.

\section{Simulation Results}

In this paper, the test system contains ten thermal units and two wind farms and this system is generalized from a certain region power system in South China. The scheduling period is one day divided into 24 intervals. The operating parameters of thermal units are listed in Table $\mathbf{1}$, and the load and the wind power output predicted are shown in Table 2. In PSO algorithm, constant $\omega=1.2$, learning factor $\mathrm{C} 1=\mathrm{C} 2=1.8$. And the programming work is done on the program Visual Studio 2010.

When the whole procedure is completed, there are two results in solution space of the unit commitment set. The results indicate different scheduling plan. They are respectively shown in Table 3 and Table 4 . These two results both meet the spinning reserve demand when the wind power accesses to power system and the constraints of system operation. The operating costs are $\$ 74,063.9$, and lower than that of plan2 whose costs are $\$ 75,764.5$. It can be seen that plan 1 is indeed slightly better than plan 2. Therefore generation scheduling plan 1 is the final result this method proposes and the histogram of unit power output is shown in Figure 1.

In the result, some power generation units, which show better power economy and lower fuel consumption, are operating all the time in the period. During the load peak period, some small and medium-sized thermal units, which have better performance in peaking regulation, help track the load change, while large units keep steady outputs. So in this generation scheduling, the regulation ability of all the thermal generators is stronger and can deal with the possible fluctuation of wind power.

With the optimized process running step by step, constraints are continuously inspected and power output of each unit keeps corrected. In the solution space, the number of the entire unit state is controlled within a reasonable range to ensure that the algorithm continues.

The results meet the system power balance requirements, and the costs of thermal power units in each period can be controlled by particle swarm optimization and meanwhile the thermal power units have sufficient spinning reserve capacity. So the results of this case can verify the feasibility and rationality of the solving process proposed.

Table 1. $P$ parameters of the thermal units.

\begin{tabular}{|c|c|c|c|c|c|}
\hline & Unit1 & Unit2 & Unit3 & Unit4 & Unit5 \\
\hline $\mathrm{P}_{\max }(\mathrm{MW})$ & 350 & 350 & 350 & 330 & 330 \\
\hline $\mathrm{P}_{\min }(\mathrm{MW})$ & 170 & 170 & 170 & 165 & 165 \\
\hline $\mathrm{a}(\$ / \mathrm{h})$ & 671 & 671 & 671 & 374 & 374 \\
\hline b(\$/MWh) & 10.1 & 10.1 & 10.1 & 8.7 & 8.7 \\
\hline \multirow[t]{2}{*}{$\mathrm{c}\left(\$ / \mathrm{MW}^{2} \mathrm{~h}\right)$} & 0.00029 & 0.00029 & 0.00029 & 0.00113 & 0.00113 \\
\hline & Unit6 & Unit7 & Unit8 & Unit9 & Unit10 \\
\hline $\mathrm{P}_{\max }(\mathrm{MW})$ & 250 & 220 & 220 & 150 & 120 \\
\hline $\mathrm{P}_{\min }(\mathrm{MW})$ & 85 & 66 & 66 & 40 & 40 \\
\hline $\mathrm{a}(\$ / \mathrm{h})$ & 270 & 230 & 230 & 320 & 209 \\
\hline $\mathrm{b}(\$ / \mathrm{MWh})$ & 8.8 & 9.9 & 9.9 & 12.4 & 12.1 \\
\hline$c\left(\$ / M W^{2} h\right)$ & 0.0022 & 0.0055 & 0.0055 & 0.0023 & 0.0019 \\
\hline
\end{tabular}

Table 2. Load and wind power .

\begin{tabular}{ccccccccc}
\hline $\mathrm{T}$ & $\begin{array}{c}\text { Load } \\
(\mathrm{MW})\end{array}$ & $\begin{array}{c}\text { Wind } \\
\text { Power(MW) }\end{array}$ & $\mathrm{T}$ & $\begin{array}{c}\text { Load } \\
(\mathrm{MW})\end{array}$ & $\begin{array}{c}\text { Wind } \\
\text { Power(MW) }\end{array}$ & $\mathrm{T}$ & $\begin{array}{c}\text { Load } \\
(\mathrm{MW})\end{array}$ & $\begin{array}{c}\text { Wind Pow- } \\
\text { er(MW) }\end{array}$ \\
\hline 1 & 1500 & 72 & 9 & 1632 & 42.1 & 17 & 1936 & 45.6 \\
2 & 1385 & 106 & 10 & 1858 & 57.1 & 18 & 1978 & 34.8 \\
3 & 1305 & 113 & 11 & 1961 & 44.0 & 19 & 1892 & 31.6 \\
4 & 1248 & 103 & 12 & 1948 & 65.4 & 20 & 1994 & 31.1 \\
5 & 1226 & 139 & 13 & 1855 & 68.6 & 21 & 2027 & 36.8 \\
6 & 1240 & 116 & 14 & 1854 & 61.6 & 22 & 1946 & 27.8 \\
7 & 1320 & 122 & 15 & 1882 & 58.9 & 23 & 1880 & 20.6 \\
\hline
\end{tabular}


Table 3. Scheduling Plan 1.

\begin{tabular}{cc}
\hline Unit & Hours(1-24) \\
\hline $1-3$ & 111111111111111111111111 \\
$4-6$ & 111111111111111111111111 \\
7 & 111111111111111111111111 \\
8 & 110000000000001111111111 \\
9 & 000000001111111111111110 \\
10 & 000000000000000000000000 \\
\hline
\end{tabular}

Table 4. Scheduling plan 2.

\begin{tabular}{cc}
\hline Unit & Hours(1-24) \\
\hline $1-3$ & 111111111111111111111111 \\
$4-6$ & 111111111111111111111111 \\
7 & 111111111111111111111111 \\
8 & 000000000000000000000000 \\
9 & 110000000000001111111111 \\
10 & 000000001111111111110000 \\
\hline
\end{tabular}

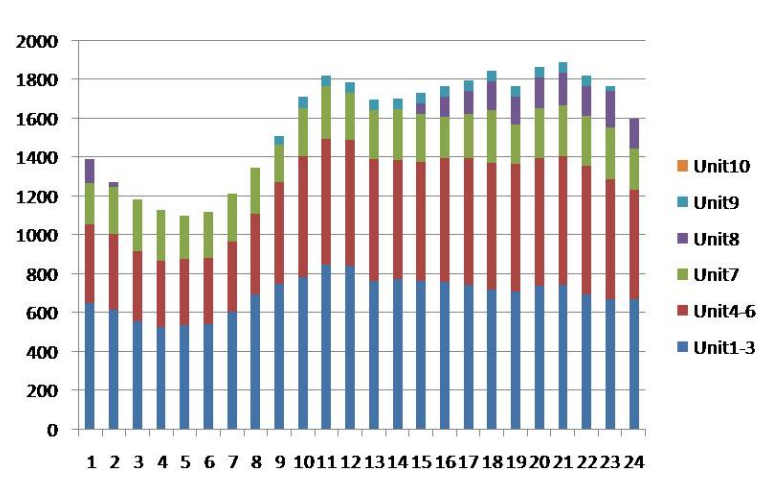

Figure 1. Result for load distribution of thermal units.

\section{Conclusions}

This paper focuses on reducing the operation costs in the wind-thermal system while the system spinning reserve constraints are met at various periods, in which wind power output keeps slightly changing. An optimization generation scheduling model is built considering power balance, reserve margin, and operating limits of thermal units.

The model is certainly a dynamic model mixed with integer variables, so a dynamic optimization method dealing with changes of unit commitment states is presented. In the searching process, the state of unit com- mitment can be updated for meeting the operation balance and reserve. The PSO algorithm is used tin load distribution of each status. The results in a test system obtained by this method shows that the generation scheduling is reasonable. The unit commitment and load dispatch can meet the power system demand and the dynamic optimization procedure works well.

\section{Acknowledgements}

The authors would like to gratefully acknowledge the contributions of the co-workers to the programming work.

\section{REFERENCES}

[1] H. Y. Chen, J. F. Chen and X. Z. Duan, "Fuzzy Modeling and Optimization Algorithm on Dynamic Economic Dispatch in Wind Power Integrated System," Automation of Electric Power Systems, Vol. 30, No. 2, 2010, pp. 22-26.

[2] M. L. Wang, B. M. Zhang and Q. Xia, "A Novel Economic Dispatching Algorithm with Unit Ramp Rate and Network Security Constraints," Automation of Electric Power Systems, Vol. 24, No.10, 2000, pp. 32-37.

[3] Y. Z. Sun, J. Wu, G. J. Li and J. He, "Dynamic Economic Dispatch Considering Wind Power Penetration Based on Wind Speed Forecasting and Stochastic Programming," Proceedings of the CSEE, Vol. 29, No. 4, 2009, pp. 23-32.

[4] T. Senjyu, "A Fast Technique for Unit Commitment Problem by Extended Priority List," IEEE Transactions on Power Systems, Vol. 18, No. 2, 2003, pp. 882-888. doi:10.1109/TPWRS.2003.811000

[5] F. N. Lee, "The Application of Commitment Utilization Factor (UFC) to the Thermal Unit Commitment," IEEE Transactions on Power Systems, Vol. 6, 1991, pp. 691-698. doi:10.1109/59.76714

[6] L. Y. Sun, Y. Zhang and C. W. Jiang, "A Solution to the Unit Commitment Problem Based on Matrix Real-coded Genetic Algorithm,” Proceedings of the CSEE, Vol. 26, No. 2, pp. 82-87, Feb. 2006.

[7] S. Chusanapiputt, D. Nualhong and S. Jantarang, "Unit Commitment by Selective Self-adaptive ACO with Relativity Pheromone Updating Approach,” Power Energy Conference, Vol. 13, No. 24, 2007, pp. 36-71.

[8] K. Han, J. Zhao and J. X. Qian, “A Closed-loop Particle Swarm Optimization Algorithm for Power System Unit Commitment," Automation of Electric Power Systems, Vol. 33, No. 1, 2009, pp. 36-40.

[9] Y. W. Jiang, C. Chen and B. Y. Wen, "Particle Swarm Research of Stochastic Simulation for Unit Commitment in Wind Farms Integrated Power System," Transactions Of China Electro Technical Society, Vol. 24, No. 6, 2009, pp. 129-137.

[10] R. Q. Li and Z. Qin, “The Optimization Operation of Unit Commitment by Considering System Reliability,” Modern Electric Power, Vol. 29, No. 2, 2012, pp. 44-49. 
[11] Yang Xiuyuan, Xiao Yang and Chen Shuyong, "Wind Speed and Generated Power Forecasting in wind Farm," Proceedings of the CSEE, vol. 25, No.11, pp. 1-5, June 2005.
[12] Chun-Lung Chen, “Optimal Wind-Thermal Generating Unit Commitment," IEEE Transactions on energy Conversion, vol. 23, No. 1, Mar. 2008.doi:10.1109/TEC.2007.914188 